\begin{tabular}{|c|c|c|c|c|}
\hline JURNAL & \multirow{2}{*}{ VOLUME 1 } & NOMOR 2 & HALAMAN 70-141 & $\begin{array}{l}\text { ISSN 2655-8823 }(p) \\
\text { ISSN 2656-1786 }(e)\end{array}$ \\
KOLABORASI RESOLUSI KONFLIK & H
\end{tabular}

\title{
PENERAPAN TERAPI PERILAKU KOGNITIF TERHADAP PENARIKAN SOSIAL PENYANDANG DISABILITAS FISIK DI DESA CAMPAKA, KABUPATEN ANDIR, BANDUNG
}

\author{
Rini Hartini Rinda Andayani \\ Politeknik Kesejahteraan Sosial Bandung \\ E-mail: rini_stks@yahoo.co.id \\ Puspa Sari Muraidandini \\ Politeknik Kesejahteraan Sosial Bandung \\ E-mail: dniecantik@yahoo.com
}

\author{
Azlinda Azman \\ School of Social Sciences Universiti Sains Malaya \\ E-mail: azlindaa@usm.my
}

\begin{abstract}
ABSTRAK
Penyandang disabilitas fisik seringkali harus berurusan dengan masalah yang berasal dari dalam dirinya sendiri, dan juga dari lingkungannya. Kecenderungan menarik diri dari lingkungan disebabkan pemahaman bahwa ia berbeda dari orang lain, dan juga lingkungan memberikan perlakukan yang berbeda terhadap mereka. Pola pikir negatif tersebut kemudian mempengaruhi perilaku menjadi mal adaptif. Kondisi ini memerlukan perhatian agar penyandang disabilitas dapat terbebas dari distorsi kognitif atau pemikiran negatif dan perilaku mal adaptif, sehingga dapat berdampak pada peningkatan kualitas hidup dirinya dan juga keluarganya. Tujuan dari penelitian ini adalah untuk mengetahui dan menganalisis 1) karakteristik responden penyandang disabilitas fisik, 2) penerapan CBT dalam mengurangi perilaku mengasingkan diri, 3) penerapan CBT dalam mengatasi perilaku yang cepat tersinggung, 3) penerapan CBT dalam mengatasi perilaku apatis, 4) penerapan CBT mengatasi perilaku sering melamun. Penelitian ini menggunakan pendekatan kuantitatif dengan desain subjek tunggal (SSD) dan model A-B-A. Teknik pengumpulan data utama dengan menggunakan kuesioner, dilengkapi dengan observasi dan wawancara. Pengujian hipotesis menggunakan analisis statistik deskriptif dengan analisis dalam kondisi dan analisis antar kondisi. Hasil penelitian menunjukkan bahwa penerapan CBT dapat mengurangi perilaku mengasingkan diri, perilaku cepat tersinggung, apatis dan perilaku yang sering melamun. Implikasi praktis dari penelitian ini menunjukkan bahwa penerapan CBT pada penyandang disabilitas fisik harus mempertimbangkan keterlibatan keluarga, terapi dilakukan dalam kelompok, kombinasi teknik penguatan yang berulang, serta kemampuan terapis untuk mengubah pemikiran negatif.
\end{abstract}

Kata kunci: cognitive behavior therapy, perilaku menarik diri, penyandang disabilitas fisik

\section{PENDAHULUAN}

Persoalan kedisabilitasan merupakan masalah sosial global, artinya masalah ini selalu berada di wilayah manapun di dunia ini. Manusia dalam proses kehidupannya dari mulai bayi hingga usia lanjut selalu akan berhadapan dengan resiko yang memungkinkannya menjadi penyandang disabilitas. Adanya risiko menjadi penyandang disabilitas, maka sudah seharusnya semua orang melakukan upaya pencegahan dan meminimalkan risiko agar tidak menjadi disabilitas, serta melakukan upaya-upaya agar penyandang disabilitas dapat hidup lebih berkualitas, berpartisipasi setara dengan yang lainnya dalam persamaan hak.

Permasalahan disabilitas sering membawa kesan munculnya permasalahan lain dalam kehidupan seseorang, yaitu permasalahan sosial dan psikologis. Fakta tersebut diungkapkan United Nations ESCAP (2002) bahwa penyandang 


\begin{tabular}{|c|c|c|c|c|}
\hline JURNAL & \multirow{2}{*}{ VOLUME 1 } & NOMOR 2 & HALAMAN 70-141 & $\begin{array}{l}\text { ISSN 2655-8823 }(p) \\
\text { ISSN 2656-1786 }(e)\end{array}$ \\
\hline KOLABORASI RESOLUSI KONFLIK & H
\end{tabular}

disabilitas berhadapan dengan berbagai bentuk diskriminasi dan kecurigaan terkait kondisi disabilitasnya. Penghargaan pada kesempurnaan fisik yang menarik seringkali dominan, sehingga penyandang disabilitas dinilai sebagai warga negara "kelas dua" (second class) yang terpinggirkan dari berbagai aspek layanan sosial yang diperlukan. Lingkungan tidak selalu kondusif menerima kehadiran penyandang disabilitas. Penolakan, kecurigaan atas rendahnya potensi diri, serta diskriminasi adalah sebagian reaksi lingkungan sekitar yang terkadang sering harus dihadapi oleh penyandang disabilitas. Penyandang disabilitas fisik yang secara mental mereka sehat dan indera sensorik mereka baik, sudah tentunya dapat merasakan langsung reaksi lingkungan terhadap dirinya. Situasi lingkungan dapat menjadi beban psikologis bagi penyandang disabilitas yang dapat berdampak pada penurunan kualitas hidup. Beban psikologis juga akibat kurangnya dukungan sosial dari orang-orang terdekat seperti keluarga dan teman. Rendahnya pemahaman potensi diri dan ketidaktahuan untuk mengembangkan potensi diri, sehingga sebagian dari penyandang disabilitas menarik diri dari lingkungan, memiliki perasaan rendah diri, merasa tidak disukai dan tidak diterima keberadaannya oleh lingkungannya. Hasil penelitian lain turut menunjukkan masalah-masalah yang berkaitan dengan sosial dan psikologis yang kerap dirasakan penyandang disabilitas. Masalah rendah diri, konsep diri yang buruk, ketidakstabilan emosi, hambatan perkembangan pada kanakkanak disabilitas, merupakan bagian dari masalah psikologis penyandang disabilitas (Turner \& Noh, 1988; Marchant, 2001; O'Loughlin, 2008).

Kesadaran akan diri yang berbeda sehingga membangun konsep diri yang buruk dan juga kesadaran akan reaksi lingkungan sekitar, seringkali menjadi penghambat penyandang disabilitas usia produktif untuk mengembangkan diri atau berpartisipasi dalam kehidupan kemasyarakatan. Kondisi ini nampak pada beberapa penyandang disabilitas fisik usia produktif di Kelurahan Kecamatan Andir Kota Bandung. Lima orang penyandang disabilitas usia produktif telah menjadi sasaran dampingan dari pekerja sosial, hasilnya menunjukkan adanya perubahan sedikit dalam hal motivasi untuk maju. Namun demikian tetap saja sebagian besar dari mereka menarik diri dari lingkungan sosial. Mereka masih menampakkan perilaku mal adaptif seperti menghabiskan waktu lama di kamar, tidak mau berinteraksi, mudah tersinggung atau mudah marah, membesar-besarkan kekurangan dirinya dan sensitif. Perilaku tersebut dipicu oleh pemikiran bahwa lingkungan tidak membutuhkan dan tidak ada harapan lagi untuk masa depannya.

Profesi pekerjaan sosial adalah profesi yang menekankan pada interaksi orang dengan lingkungannya agar tercipta keberfungsian sosial. Pekerja sosial dapat membantu meningkatkan keberfungsian sosial penyandang disabilitas, sehingga dapat memiliki kualitas hidup yang lebih baik yang akan berdampak pula pada peningkatan kualitas hidup atau kesejahteraan keluarganya. Penggunaan teknik cognitive behavioral therapy (CBT) merupakan salah satu teknik dalam terapi psikososial yang dapat digunakan oleh pekerja sosial klinis. Masalah yang dapat disentuh penyelesaiannya melalui penggunaan terapi psikososial antara lain persoalan-persoalan stigma, perilaku kelompok, pengaruh lingkungan, kebutuhan akan ruang pribadi, serta perubahan personal dan sosial (Zastrow, 2002). Adapun tujuan dari terapi psikososial adalah memberikan kontribusi pada pencapaian kepuasan, memenuhi keberfungsian manusia dalam kerangka nilai-nilai pribadi, dan mengakses sumbersumber yang tersedia dalam masyarakat (Turner, 1978). CBT dapat menjadi tepat untuk penyandang disabilitas fisik karena kemampuan kognitif mereka tidak terganggu hanya saja terdistorsi oleh pemikiran-pemikiran negatif. CBT 


\begin{tabular}{|c|c|c|c|c|}
\hline JURNAL & \multirow{2}{*}{ VOLUME 1 } & NOMOR 2 & HALAMAN 70-141 & $\begin{array}{l}\text { ISSN 2655-8823 }(p) \\
\text { ISSN 2656-1786 }(e)\end{array}$ \\
\hline KOLABORASI RESOLUSI KONFLIK
\end{tabular}

digunakan dalam penelitian ini ditujukan untuk merubah perilaku menarik diri klien dan merubah pemikiran yang terdistorsi, sehingga klien dapat mengembangkan diri dan potensinya yang akan berdampak pada peningkatan kualitas hidupnya.

\section{METODE}

Penelitian ini menggunakan pendekatan kuantitatif dengan jenis rancangan eksperimen yang digunakan adalah rancangan subjek tunggal (Single Subject Design). Bellini \& Akullian, (2007) mengemukakan bahwa didalam paradigma modifikasi perilaku, rancangan subjek tunggal telah menjadi pendekatan eksperimental yang paling menonjol. Menurut Horner,dkk (2005, dalam Bellini dan Akullian, 2007), rancangan penelitian dengan subjek tunggal di pandang sebagai desain yang sesuai untuk studi yang melibatkan subjek yang membutuhkan pelayanan khusus. Subjek penelitian ini adalah laki-laki berusia 26 tahun, penyandang disabilitas fisik, yang bertempat tinggal di Kelurahan Campaka, Kecamatan Andir Kota Bandung.

Desain A-B-A diimplementasikan untuk mengevaluasi pelaksanaan dan pencapaian suatu tujuan intervensi melalui pengukuran secara berulang. Pengukuran berulang dilakukan sebelum pada masa baseline dan setelah intervensi diterapkan. Pengumpulan data utama dilakukan dengan pengisian kuesioner, disertai dengan teknik observasi serta wawancara. Data juga diperoleh dengan pengukuran menggunakan instrumen asesmen kognitif, asesmen perilaku dan instrumen baku yakni social withdrawall scale yang terdapat dalam Personality Inventory For Youth (PIY) yang dikembangkan oleh David Lachar dan Cristian P. Gruber pada tahun 1993.

Uji validitas alat ukur yang digunakan dalam penelitian ini adalah validitas isi (conten validity) yaitu sejauh mana butir tes mencakup keseluruhan indikator, kompetensi yang dikembangkan dari materi atau bahan yang ingin diukur. Pengujian alat ukur yang digunakan dalam penelitian ini adalah teknik korelasi pearson product moment, dengan menggunakan SPSS realease 18.0 for window. Adapun uji reliabilitas alat ukur yang digunakan dalam penelitian ini adalah metode analisis internal consistency, dengan teknik uji koefisien Alfa Cronbach.

Analisis penelitian ini menggunakan analisis dalam kondisi dan analisis antar kondisi. Pada masing masing analisis digunakan statistik deskriptif sebagai alatnya.

a. Analisis dalam kondisi, meliputi: 1) panjang kondisi, 2) estimasi kecenderungan arah, 3) kecenderungan stabilitas, 4) jejak data, level stabilitas dan rentang, serta 5) level perubahan.

b. Analisis antar kondisi, meliputi: 1) jumlah variabel yang diubah, 2) perubahan kecenderungan dan efeknya, 3) perubahan stabilitas, 4) perubahan level, dan 5) data overlap.

\section{Hipotesis Penelitian}

$\mathrm{H} 1$ : Cognitive Behaviour Therapy berpengaruh terhadap masalah menarik diri klien "B" penyandang disablitas tubuh. $\mathrm{H} 0$ : Cognitive Behaviour Therapy tidak berpengaruh terhadap masalah menarik diri klien "B" penyandang disabilitas tubuh.

Sub Hipotesis :

a. $\mathrm{H}_{1}^{1}$ : CBT berpengaruh pada perilaku mengasingkan diri klien "B".

$\mathrm{H}_{0}^{1}$ : CBT tidak berpengaruh pada perilaku mengasingkan diri klien "B".

b. $\mathrm{H}_{1}^{2}$ : $\mathrm{CBT}$ berpengaruh pada perilaku mudah tersinggung klien "B".

$\mathrm{H}_{0}^{2}$ : CBT tidak berpengaruh pada perilaku mudah tersinggung klien "B".

c. $\mathrm{H}_{1}^{3}$ : CBT berpengaruh pada perilaku apatis klien " $\mathrm{B}$ ".

$\mathrm{H}_{0}^{3}$ : $\mathrm{CBT}$ tidak berpengaruh perilaku apatis klien "B".

d. $\mathrm{H}_{1}^{4}$ : CBT berpengaruh pada perilaku sering melamunklien " $\mathrm{B}$ ". 


\begin{tabular}{|c|c|c|c|c|}
\hline JURNAL & \multirow{2}{*}{ VOLUME 1 } & NOMOR 2 & HALAMAN 70-141 & $\begin{array}{l}\text { ISSN 2655-8823 }(p) \\
\text { ISSN 2656-1786 }(e)\end{array}$ \\
\hline
\end{tabular}

$\mathrm{H}_{0}^{4}$ : CBT tidak berpengaruh pada perilaku sering melamun klien " $\mathrm{B}$ "

\section{Proses Penelitian}

Prosedur penelitian menggunakan model desain A-B-A, dengan tujuan akan nampak perbedaan sebelum dan sesudah penerapan model, sebagai berikut :

1. Fase Baseline (A1)

Pada fase ini dilakukan pengumpulan dan pencatatan data dasar yang menggambarkan perilaku natural dari subjek. Pengumpulan data dilakukan dengan melakukan pengukuran awal sebagai asesmen awal melalui pengisian skala social withdrawal. Kemudian dalam penelitian ini dilakukan pengukuran distorsi kognitif, serta pengukuran terhadap aspek-aspek perilaku menarik diri.

2. Fase Intervensi (B)

Pada fase ini subjek diberikan intervensi dengan teknik CBT pada masing-masing target perilaku menarik diri yaitu perilaku mengasingkan diri, perilaku mudah tersinggung. perilaku apatis, dan perilaku sering melamun. Peneliti melibatkan kelompok sebaya dari lingkungan ketetanggan yang mau untuk membantu dalam proses terapi. Adapun langkah-langkah yang dilakukan dalam penerapan intervesni melalui teknik CBT adalah sebagai berikut :

a. Asesmen dan diagnosa.

b. Mencari akar permasalahan yang bersumber dari emosi negatif, distorsi kognitif atau pikiran negatif.

c. Menyusun rencana intervensi dengan memberikan konsekuensi positif-negatif kepada klien

d. Menata kembali keyakinan yang menyimpang / menstruktur proses berpikir positif.

e. Perubahan Core Belief dengan cara menolak pemikiran yang terdistorsi dengan menggunakan terapi realitas

f. Intevensi tingkah laku, menggunakan possitive reinforcement

g. Pencegahan relapse atau kembali pada perilaku sebelumnya.

\section{Fase Baseline 2 (A2)}

Fase Baseline 2 merupakan tahapan akhir yang menggambarkan kondisi subjek penelitian setelah diberikan intervensi, pada fase baseline 2 peneliti dapat melihat hasil dari intervensi yang dilakukan dalam 7 (tujuh) sesi tersebut dan mengevaluasi hasilnya melalui pengukuran dan observasi perubahan perilaku dan cara berpikir klen " $\mathrm{B}$ ".

\section{HASIL DAN PEMBAHASAN Karakteristik responden}

Klien "B" laki-laki berusia 26 tahun, merupakan anak ke lima dari enam bersaudara. B mengalami disabilitas diawali pada usia 15 tahun setelah mengalami kejang otot pada tangan kiri serta kaki kiri sehingga kaku. B berjalan di geser karena kelumpuhannya tersebut, dan seehari-harinya B berjalan dengan menggunakan kursi plastik sebagai penopang berat tubuhnya. B masih dapat melakukan aktifitas kehidupan sehari-hari secara mandiri walaupun agak kaku, seperti makan, minum, mandi atau membersihkan diri, namun demikian sehari harinya B hanya berdiam diri saja di rumah bahkan sering mengurung diri di dalam kamarnya tanpa melakukan kegiatan apapun. Menurut keluarganya sebelum menjadi disabilitas B cukup aktif sekolah dan aktif di masyarakat, namun sekarang B menjadi orang yang tertutup dan cepat tersinggung. B sehari-hari nampak pasrah dengan kondisinya, lebiih sering berdiam diri, dan sering menutup diri dari lingkungannya. B jarang sekali mengikuti aktivitas sosial seperti berinteraksi dengan tetangga. B sebenarnya memiliki harapan dan impian bahwa suatu saat ingin menikah, bisa mandiri dan menghasilkan uang sendiri. 


\begin{tabular}{|c|c|c|c|c|}
\hline $\begin{array}{c}\text { JURNAL } \\
\text { KOLABORASI RESOLUSI KONFLIK }\end{array}$ & VOLUME 1 & \multirow{2}{*}{ NOMOR 2 } & HALAMAN 70-141 & $\begin{array}{c}\text { ISSN 2655-8823 }(p) \\
\text { ISSN 2656-1786 }(e)\end{array}$ \\
\hline
\end{tabular}

The application of CBT in reducing the behavior of isolation

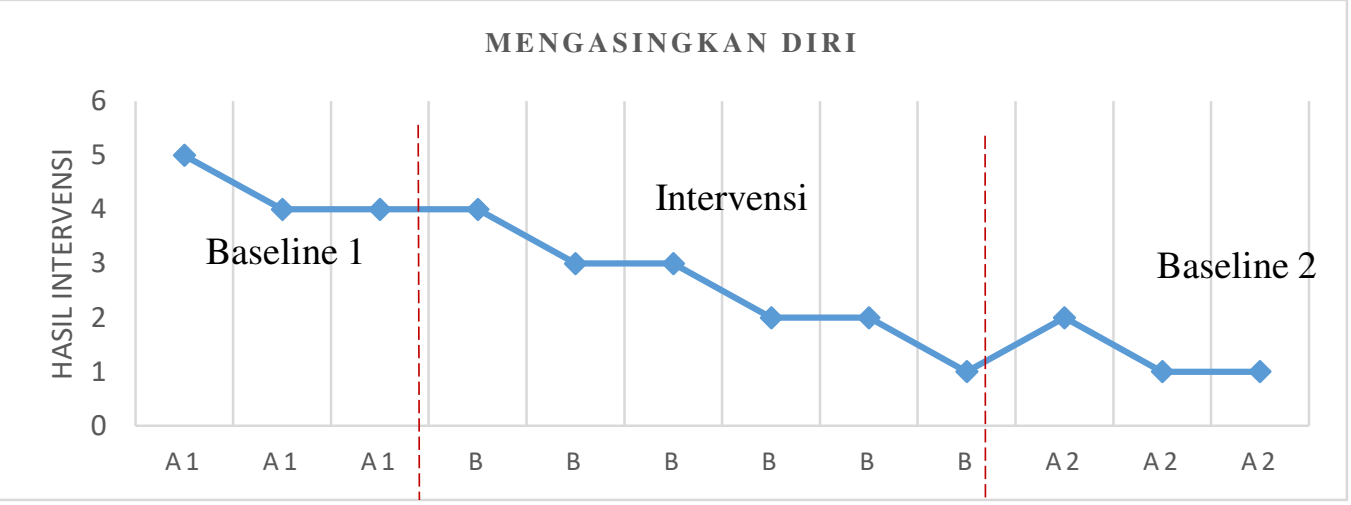

Grafik 1 Intervensi CBT pada perilaku mengasingkan diri

Dari grafik di atas nampak penurunan kemunculan target perilaku mengasingkan diri, dan pada baseline 2 nampak stabil pada arah positif. selanjutnya dilakukan analisis dalam kondisi dan analisis antar kondisi, seperti dalam tabel berikut:

Analisis dalam kondisi

\begin{tabular}{|l|c|c|c|}
\hline \multicolumn{1}{|c|}{ Kondisi } & A1 & B & A2 \\
\hline Panjang kondisi & 3 & 6 & 3 \\
\hline $\begin{array}{l}\text { Kecenderungan } \\
\text { arah }\end{array}$ & - & - & \\
\hline Jejak data & $(+)$ & $(+)$ & $(+)$ \\
\hline $\begin{array}{l}\text { Stabilitas dan } \\
\text { rentang }\end{array}$ & $5-4(+)$ & $4-3(+)$ & $\begin{array}{c}1-1 \\
(=)\end{array}$ \\
\hline Perubahan level & $\begin{array}{c}5-4 \\
(+1)\end{array}$ & $\begin{array}{c}4-1 \\
(+3)\end{array}$ & $\begin{array}{c}1-1 \\
(0)\end{array}$ \\
\hline
\end{tabular}

Analisis antar kondisi

\begin{tabular}{|l|l|}
\hline $\begin{array}{l}\text { Kondisi yang } \\
\text { dibandingkan }\end{array}$ & \multicolumn{1}{|c|}{ Baseline ke Intervensi } \\
\hline $\begin{array}{l}\text { Perubahan arah } \\
\text { dan efeknya }\end{array}$ & $(+) \quad$ ke \\
\hline $\begin{array}{l}\text { Perubahan } \\
\text { stabilitas }\end{array}$ & Stabil ke arah positif (+) \\
\hline Perubahan level & $\begin{array}{l}\text { Skor awal pada intervensi } \\
\text { dikurangi skor terakhir pada } \\
\text { baseline } \\
(3-1)=2\end{array}$ \\
\hline
\end{tabular}

The application of CBT in overcoming the behavior quickly offended

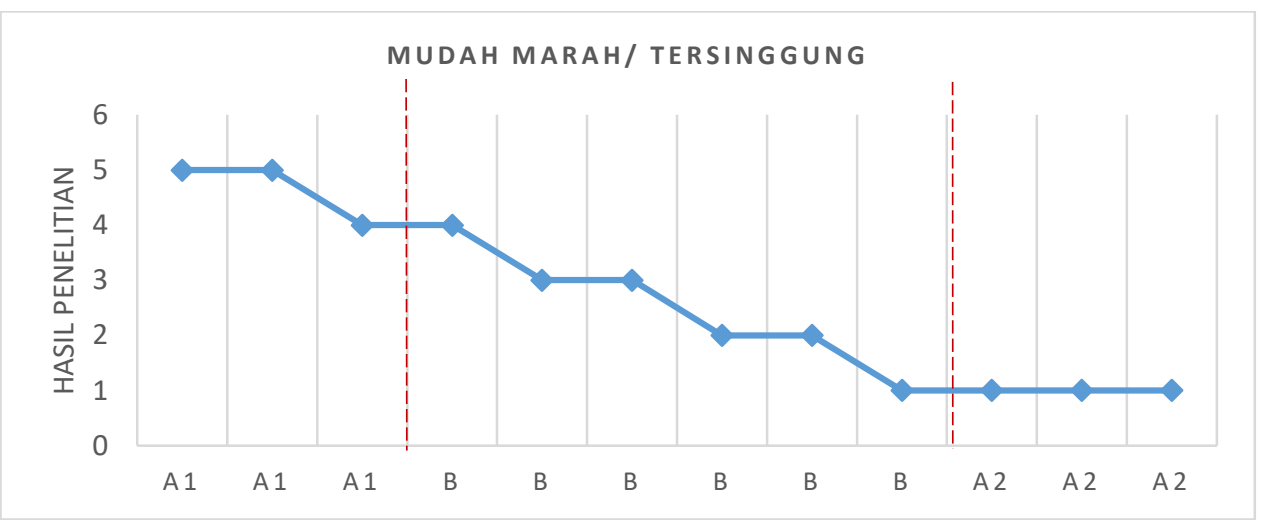

Grafik 2 Intervensi CBT pada perilaku cepat tersinggung

Dari grafik di atas nampak penurunan kemunculan target perilaku sering mudah tersinggung, dan pada sesi baseline 2 nampak kondisi stabil ke arah positif. selanjutnya dilakukan analisis dalam kondisi dan analisis antar kondisi, seperti dalam tabel berikut: 


\begin{tabular}{|c|c|c|c|c|}
\hline $\begin{array}{c}\text { JURNAL } \\
\text { KOLABORASI RESOLUSI KONFLIK }\end{array}$ & VOLUME 1 & \multirow{2}{*}{ NOMOR 2 } & HALAMAN 70-141 & $\begin{array}{c}\text { ISSN 2655-8823 }(p) \\
\text { ISSN 2656-1786 }(e)\end{array}$ \\
\hline
\end{tabular}

- Analisis dalam kondisi

\begin{tabular}{|l|c|c|c|}
\hline \multicolumn{1}{|c|}{ Kondisi } & A1 & B & A2 \\
\hline Panjang kondisi & 3 & 6 & 3 \\
\hline $\begin{array}{l}\text { Kecenderungan } \\
\text { arah }\end{array}$ & - & - & (t) \\
\hline Jejak data & $(+)$ & $(+)$ & $(=)$ \\
\hline $\begin{array}{l}\text { Stabilitas dan } \\
\text { rentang }\end{array}$ & $5-4(+)$ & $4-3(+)$ & $\begin{array}{c}1-1 \\
(=)\end{array}$ \\
\hline Perubahan level & $\begin{array}{c}5-4 \\
(+1)\end{array}$ & $\begin{array}{c}4-1 \\
(+3)\end{array}$ & $\begin{array}{c}1-1 \\
(0)\end{array}$ \\
\hline
\end{tabular}

Analisis antar kondisi

\begin{tabular}{|l|l|}
\hline $\begin{array}{l}\text { Kondisi yang } \\
\text { dibandingkan }\end{array}$ & \multicolumn{1}{|c|}{ Baseline ke Intervensi } \\
\hline $\begin{array}{l}\text { Perubahan arah } \\
\text { dan efeknya }\end{array}$ & $(+)$ \\
\hline $\begin{array}{l}\text { Perubahan } \\
\text { stabilitas }\end{array}$ & Stabil ke arah positif (+) \\
\hline Perubahan level & $\begin{array}{l}\text { Skor awal pada intervensi } \\
\text { dikurangi skor terakhir pada } \\
\text { baseline } \\
(3-1)=2\end{array}$ \\
\hline
\end{tabular}

\section{The application of CBT in overcoming apathy behavior}

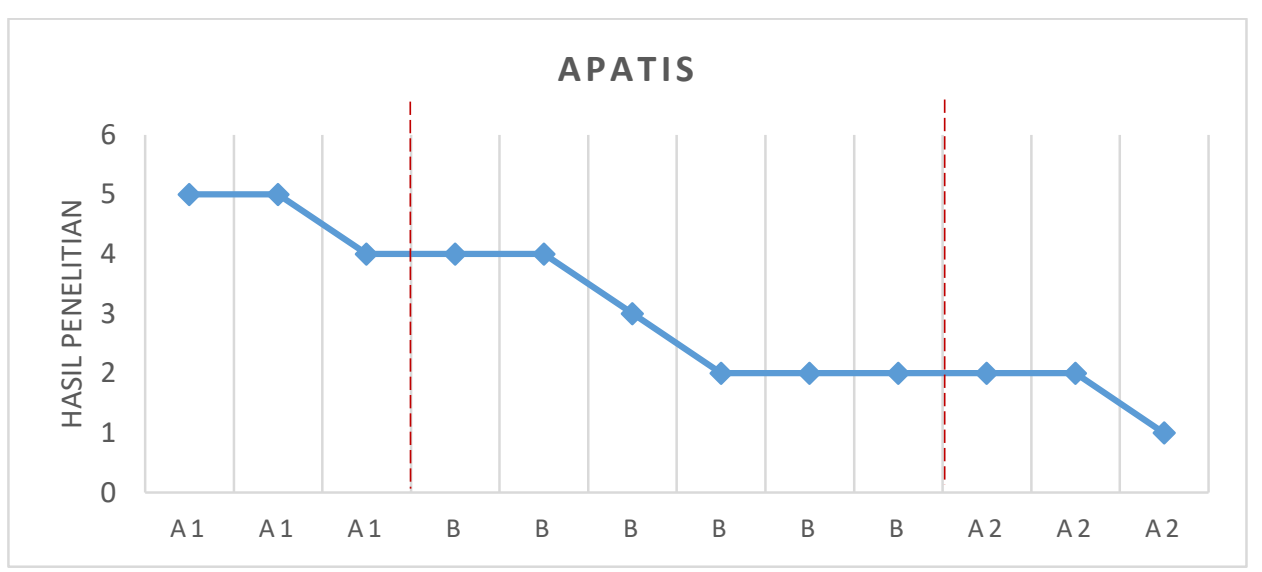

Grafik 3 Intervensi CBT terhadap perilaku apatis

Dari grafik di atas nampak penurunan kemunculan target perilaku apatis, dan pada sesi baseline 2 nampak kondisi menurun ke arah positif. selanjutnya dilakukan analisis dalam kondisi dan analisis antar kondisi, seperti dalam tabel berikut:

Analisis dalam kondisi

\begin{tabular}{|l|c|c|c|}
\hline \multicolumn{1}{|c|}{ Kondisi } & A1 & B & A2 \\
\hline Panjang kondisi & 3 & 6 & 3 \\
\hline $\begin{array}{l}\text { Kecenderungan } \\
\text { arah }\end{array}$ & - & - & - \\
\hline Jejak data & $(+)$ & $(+)$ & $(+)$ \\
\hline $\begin{array}{l}\text { Stabilitas dan } \\
\text { rentang }\end{array}$ & $5-4(+)$ & $4-2(+)$ & $2-1(+)$ \\
\hline Perubahan level & $\begin{array}{c}5-4 \\
(+1)\end{array}$ & $\begin{array}{c}4-2 \\
(+2)\end{array}$ & $\begin{array}{c}2-1 \\
(+1)\end{array}$ \\
\hline
\end{tabular}

Analisis antar kondisi

\begin{tabular}{|l|c|}
\hline \multicolumn{1}{|c|}{$\begin{array}{l}\text { Kondisi yang } \\
\text { dibandingkan }\end{array}$} & \multicolumn{1}{|c|}{ Baseline : Intervensi } \\
\hline $\begin{array}{l}\text { Perubahan arah } \\
\text { dan efeknya }\end{array}$ & $(+)$ \\
\hline $\begin{array}{l}\text { Perubahan } \\
\text { stabilitas }\end{array}$ & Stabil ke arah positif (+) \\
\hline Perubahan level & $\begin{array}{l}\text { Skor awal pada intervensi } \\
\text { dikurangi skor terakhir pada } \\
\text { baseline } \\
(2-1)=1\end{array}$ \\
\hline
\end{tabular}




\begin{tabular}{|c|c|c|c|c|}
\hline $\begin{array}{c}\text { JURNAL } \\
\text { KOLABORASI RESOLUSI KONFLIK }\end{array}$ & VOLUME 1 & \multirow{2}{*}{ NOMOR 2 } & HALAMAN 70-141 & $\begin{array}{c}\text { ISSN 2655-8823 }(p) \\
\text { ISSN 2656-1786 }(e)\end{array}$ \\
\hline
\end{tabular}

The application of CBT overcome behavior often daydreaming.

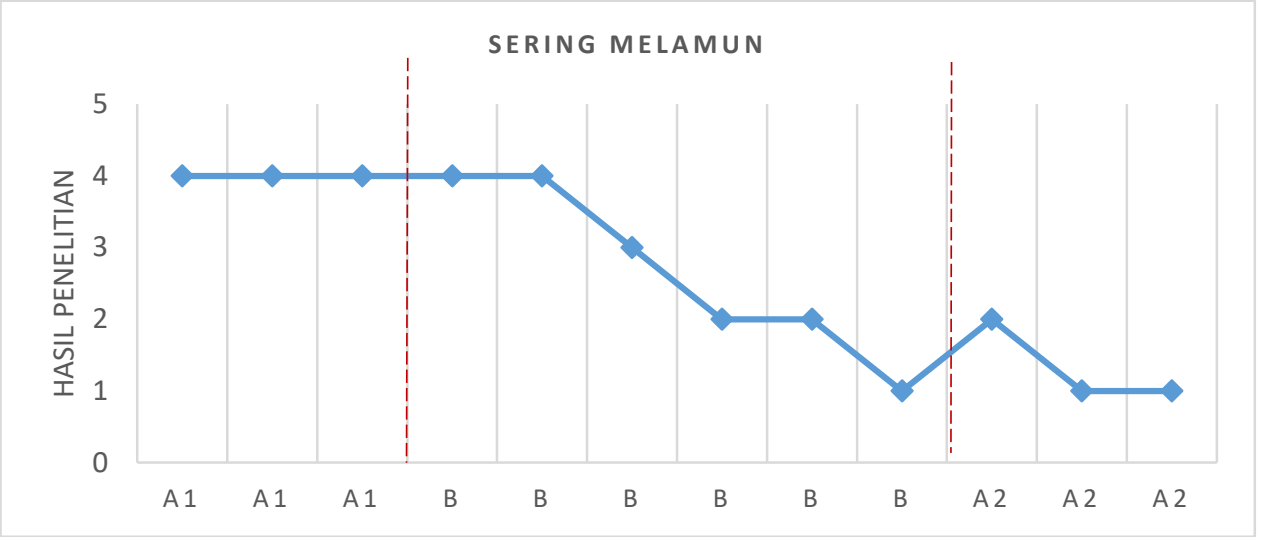

Grafik 4 Intervensi CBT pada perilaku sering melamun

Dari grafik di atas nampak penurunan kemunculan target perilaku sering melamun dan pada sesi baseline 2, walaupun terdapat data overlap namn akhirnya nampak kondisi stabil ke arah positif. selanjutnya dilakukan analisis dalam kondisi dan analisis antar kondisi, seperti dalam tabel beriku

Analisis dalam kondisi

\begin{tabular}{|c|c|c|c|}
\hline Kondisi & A1 & $\mathrm{B}$ & $\mathrm{A} 2$ \\
\hline Panjang kondisi & 3 & 6 & 3 \\
\hline $\begin{array}{l}\text { Kecenderungan } \\
\text { arah }\end{array}$ & & & \\
\hline Jejak data & $(=)$ & $\underset{(+)}{ }$ & $(+)$ \\
\hline $\begin{array}{l}\text { Stabilitas dan } \\
\text { rentang }\end{array}$ & $4-4(=)$ & $4-2(+)$ & $\begin{array}{c}2-1 \\
(+)\end{array}$ \\
\hline Perubahan level & $4-4(0)$ & $\begin{array}{l}4-1 \\
(+3)\end{array}$ & $\begin{array}{l}2-1 \\
(1)\end{array}$ \\
\hline
\end{tabular}

Analisis antar kondisi

\begin{tabular}{|l|l|}
\hline $\begin{array}{l}\text { Kondisi yang } \\
\text { dibandingkan }\end{array}$ & \multicolumn{1}{|c|}{ Baseline : Intervensi } \\
\hline $\begin{array}{l}\text { Perubahan arah } \\
\text { dan efeknya }\end{array}$ & $(+)$ \\
\hline $\begin{array}{l}\text { Perubahan } \\
\text { stabilitas }\end{array}$ & Stabil ke arah positif (+) \\
\hline Perubahan level & $\begin{array}{l}\text { Skor awal pada intervensi } \\
\text { dikurangi skor terakhir pada } \\
\text { baseline } \\
(3-1)=2\end{array}$ \\
\hline
\end{tabular}

\section{CBT terhadap distorsi kognitif}

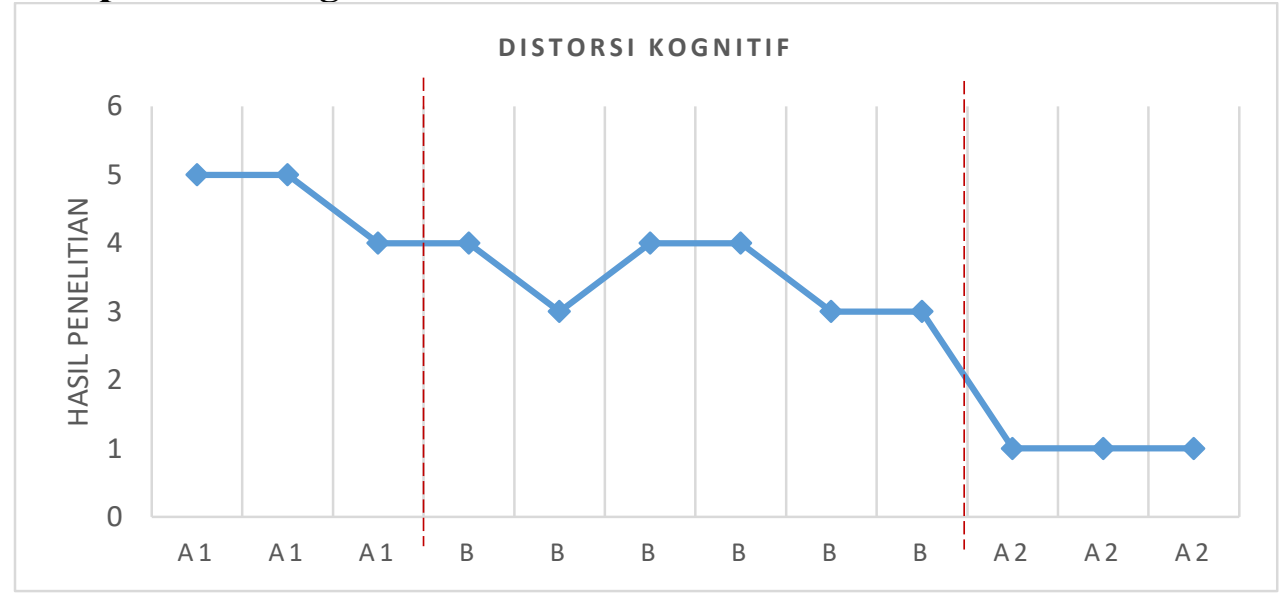

Grafik 5 Intervensi CBT pada distorsi kognitif 


\begin{tabular}{|c|c|c|c|c|}
\hline JURNAL & \multirow{2}{*}{ VOLUME 1 } & NOMOR 2 & HALAMAN 70-141 & $\begin{array}{l}\text { ISSN 2655-8823 }(p) \\
\text { ISSN 2656-1786 }(e)\end{array}$ \\
KOLABORASI RESOLUSI KONFLIK & H
\end{tabular}

Dari grafik di atas nampak penurunan kemunculan distorsi kognitif dan pada sesi baseline 2, nampak kondisi stabil ke arah positif. selanjutnya dilakukan analisis dalam kondisi dan analisis antar kondisi, seperti dalam tabel berikut:

Analisis dalam kondisi

\begin{tabular}{|c|c|c|c|}
\hline Kondisi & A1 & $\mathrm{B}$ & A2 \\
\hline Panjang kondisi & 3 & 6 & 3 \\
\hline $\begin{array}{l}\text { Kecenderungan } \\
\text { arah }\end{array}$ & $\Delta$ & $\Delta$ & \\
\hline Jejak data & $\underset{(+)}{\Delta}$ & $(=)$ & $(+)^{-1}$ \\
\hline $\begin{array}{l}\text { Stabilitas dan } \\
\text { rentang }\end{array}$ & $5-4(+)$ & $4-3(+)$ & $\begin{array}{c}3-1 \\
(+)\end{array}$ \\
\hline Perubahan level & $\begin{array}{l}5-4 \\
(+1)\end{array}$ & $\begin{array}{l}4-3 \\
(+1)\end{array}$ & $\begin{array}{c}3-1 \\
(2)\end{array}$ \\
\hline
\end{tabular}

Berdasarkan grafik dan tabel analisis hasil pengolahan SSD menunjukkan bahwa pendekatan kognitif dikombinasikan dengan perilaku akan memperkuat pembentukan perilaku baru. Kondisi ini sejalan dengan pendapat Beck (1995) menjelaskan bahwa CBT merupakan proses konseling yang bertujuan klien agar lebih sehat, dapat memperoleh pengalaman yang memuaskan untuk dapat memenuhi gaya hidup dengan memodifikasi perilaku dan pikiran.

Penyederhanaan sesi dalam CBT menjadi penting, sehingga klien tidak terlalu jenuh dan bosan dengan prosedur terapi. Sejalan dengan pendapat Oemarjoedi dalam Kassandra (2003), bahwa melihat kultur yang ada di Indonesia penerapan sesi yang berjumlah 12 sesi pertemuan dirasakan sulit untuk dilakukan, disebabkan terlalu lama, sementara klien mengharapkan hasil yang dapat segera dirasakan manfaatnya.Terlalu rumit dan membosankan. Peneliti juga memulai dari perubahan core beliefs sebelum melakukan intervensi tingkah laku, didasari pemahaman bahwa teori kognitif didasarkan bahwa adanya timbal balik antara apa yang kita pikirkan, bagaimana kita merasa dan bagaimana kita berperilaku.

\section{Analisis antar kondisi}

\begin{tabular}{|l|l|}
\hline $\begin{array}{l}\text { Kondisi yang } \\
\text { dibandingkan }\end{array}$ & \multicolumn{1}{|c|}{ Baseline : Intervensi } \\
\hline $\begin{array}{l}\text { Perubahan arah } \\
\text { dan efeknya }\end{array}$ & $(+) \quad$ ke \\
\hline $\begin{array}{l}\text { Perubahan } \\
\text { stabilitas }\end{array}$ & $\begin{array}{l}\text { Stabil ke arah positif (+) } \\
\text { Perubahan level } \\
\text { dikurangi skor terakhir pada } \\
(1-1)=0\end{array}$ \\
\hline
\end{tabular}

Implikasi Praktis

Implikasi praktis yang diperoleh dari hasil penelitian ini menunjukkan bahwa aplikasi terapi perilaku kognitif orang dengan cacat fisik harus dipertimbangkan: keterlibatan keluarga, terapi yang dilakukan dalam kelompok, kombinasi teknik penguatan yang berulang, kemampuan terapis untuk mendistorsi pemikiran negatif. Tahapan proses CBT dapat digabung antara langkah ke 4 dan ke 5, sehingga proses terapi menjadi lebih mudah, yaitu menata kembali keyakinan yang menyimpang atau menstruktur proses berpikir positif dengan perubahan core belief.

CBT memiliki beberapa tahapan dengan prosedur yang ketat, sehingga untuk menghindari kebosanan pada klien perlu memperhatikan suasana proses terapi, tempat maupun waktu pelaksanaan terapi.

Penggunaan modeling sangat menunjang untuk klien disabilitas, karena membuat keyakinan bahwa penyandang disabilitas lainnya atau bahkan yang lebih berat kondisinya dapat meraih sukses.

\section{KESIMPULAN DAN SARAN Kesimpulan}

1. Penggunaan terapi CBT berpengaruh terhadap penurunan aspek-aspek 


\begin{tabular}{|c|c|c|c|c|}
\hline JURNAL & \multirow{2}{*}{ VOLUME 1 } & NOMOR 2 & HALAMAN 70-141 & $\begin{array}{c}\text { ISSN 2655-8823 }(p) \\
\text { ISSN 2656-1786 }(e)\end{array}$ \\
\hline
\end{tabular}

perilaku menarik diri yaitu perilaku mengasingkan diri, perilaku mudah tersinggung, perilaku apatis serta perilaku sering melamun.

2. Berhasilnya penggunaan terapi dapat diduga juga karena ada dukungan dari keluarga dan dari kelompok terapi yang sengaja dibentuk

3. Perubahan pola pikir dari yang terdistorsi pikiran negatif menjadi pikiran positif berpengaruh pada perubahan perilaku.

\section{Saran/Rekomendasi}

Pekerja sosial perlu membangun jaringan sumber daya di sekitar sistem klien. Keterlibatan lingkungan di sekitar klien menjadi sumber motivasi penting bagi klien individu dan keluarga. Dalam studi ini, peneliti merekrut keluarga dan kelompok teman sebaya dari lingkungan selama proses intervensi.

\section{DAFTAR PUSTAKA}

Bellini, S. \&Akalian, J. 2007. A Meta Analysis of Video Modelling and Video Self Modelling Interventions for Children and Adolescent With Autism Spectrum Disorder, Exceptional Children.

David, L., Gruber, Cristian P. 1995. Personality Inventory for Youth (PIY) Manual: Administration and Interprestation Technical Guide. Los
Angeles: Western Psychological Service (WPS).

DuBois, B.\&Miley,K.K. 2005. Social work an empowering profession. USA: Pearson Education, Inc.

RehabilitasiSosial Department, STKS Bandung. 2006. Psychosocial Therapy. Manual Part 1. Not Published.

Marchant, R.2001.Working with disabled children. In: FoleyP., RocheJ., TuckerS., editors. Children in Society: Contemporary Theory, Policy and Practice. Basingstoke: Palgrave in association with Open University Press.

O'Loughlin, M.\&O'Loughlin, S. 2008. Social Work with Children and Family. Glasgow.

Putranto, A. K. 2016. The Aplication of Cognitive Behavior and Behavior Activities in Clinical Intervention. Grafindo Books Media.

Turner, F.J. \&Noh, S. 1988. Physical disability and depression: A longitudinal analysis. Health and Social Behavior. 29 (1).

Turner, F. J. 1978. Psychosocial Therapy. New York: Macmillan Publishing Co.

Andayani, R.H.R, et al. 2011. Psychosocial Therapy. Bandung. STKS Press.

UN ESCAP.2002. Disability and the BiwakoMillenium Framework for Action.

Zastrow, C.H.\& Kirst-Ashman, Karen K. 2004. Understanding human behavior and the social environment. USA: Thomson Learning Inc. 